\title{
3D Printing of Well Dispersed Electrospun PLGA Fiber Toughened Calcium Phosphate Scaffolds for Osteoanagenesis
}

\author{
Guoru Zhao ${ }^{1}$, Rongwei Cui ${ }^{1}$, You Chen ${ }^{1}$, Sijie Zhou ${ }^{1}$, Chen Wang ${ }^{1}$, Zhangmei Hu ${ }^{2}$, Xiaoke Zheng ${ }^{2}$, \\ Maohong $\mathrm{Li}^{3^{*}}$, Shuxin Qu ${ }^{1^{*}}$ \\ 1. Key Lab of Advanced Technologies of Materials, Ministry of Education, School of Materials Science and Engineering, \\ Southwest Jiaotong University, Chengdu 610031, China \\ 2. Analytical and Testing Center, Southwest Jiaotong University, Chengdu 610031, China \\ 3. Key Lab of High-speed Railway Engineering, Ministry of Education, School of Civil Engineering, \\ Southwest Jiaotong University, Chengdu 610031, China
}

\begin{abstract}
Although the toughening of Calcium phosphate $(\mathrm{CaP})$ scaffold by the addition of fiber has been well recognized, integrated mechanical, structural and functional considerations have been neglected in the design and fabrication of CaP scaffold implant. The emerging 3D printing provides a promising technique to construct $\mathrm{CaP}$ scaffold with precise size and elaborate microstructure. However, the most challenge is to extrude smoothly the CaP paste containing fibers for frequently-used extrusion-based 3D printing. In this study, frozen section and chemical dispersant (Pluronic F127, F127) were employed jointly to prepare non-aggregated polylactic-co-glycolic acid (PLGA) fibers. The injectability of CaP pastes with well dispersed PLGA fibers was more than $90 \%$ when the content of PLGA fibers was no more than $3 \mathrm{wt} \%$. Meanwhile rheological property of $\mathrm{CaP}$ pastes with well dispersed fibers showed shear thinning, which were both beneficial to extrude $\mathrm{CaP}$ paste with well dispersed fibers for 3D printing. Moreover, these CaP scaffolds showed ductile fracture behavior due to the pullout and bridging effect of PLGA fibers. The cell proliferation and alkaline phosphatase (ALP) activity indicated that 3D printed CaP scaffold containing PLGA fibers possesses excellent biocompatibility and facilitate osteogenic differentiation ability. Thus, it was feasible to print $\mathrm{CaP}$ pastes with well dispersed PLGA fibers to construct toughening $\mathrm{CaP}$ scaffolds with the higher shape fidelity and complex structures, which had significant clinical potentials in osteoanagenesis due to their higher toughness and excellent biocompatibility.
\end{abstract}

Keywords: CaP scaffold, extrusion-based 3D printing, PLGA fiber, toughening, biocompatibility

Copyright $($ C) The author(s) 2020 .

\section{Introduction}

Calcium phosphate $(\mathrm{CaP})$ scaffold has been widely used in the field of bone defect repair owing to its similarity to the inorganic components of bone tissue, which resulted in the favorable biocompatibility and osteoconductivity $^{[1]}$. However, the most significant drawback of $\mathrm{CaP}$ scaffold is brittle and low mechanical strength, which results in its limited utilization as bone graft only for un-loaded site. Extensive studies on fiber reinforced or toughened $\mathrm{CaP}$ scaffold have been performed to enhance its mechanical properties inspired by the hierarchical structure of native bone tissue ${ }^{[2-4]}$, which consist of $\mathrm{CaP}$ and mineralized collagen fibrils ${ }^{[5]}$. Especially, electrospun fibers are used to improve the mechanical properties of $\mathrm{CaP}$ scaffold dramatically due to their analogous architecture to the structure of extracellular matrix ${ }^{[6-9]}$. In general, the electrospinning process yields nonwoven fabric or oriented fiber via rotational drum ${ }^{[6]}$. It is difficult to get the non-aggregated fibers for electrospun nonwoven fabric and oriented fiber due to the large ratio of length to diameter, which results in the intertwinement of fibers in $\mathrm{CaP}$ matrix. Some studies show that the mechanical properties of $\mathrm{CaP}$ scaffold can be influenced by the length and content of fibers, the dispersion of fiber in matrix, and interface between fiber and matrix ${ }^{[3,9-12]}$. Maenz et al. confirm that the mechanical properties of $\mathrm{CaP}$ scaffold, particularly for its Work of Fracture (WOF), increase significantly with the increasing length

*Corresponding author: Shuxin $\mathrm{Qu}$, Maohong $\mathrm{Li}$

E-mail: qushuxin@swjtu.edu.cn, sclimaohong@swjtu.edu.cn 
of fiber ${ }^{[12]}$. Additionally, partial mechanical properties of $\mathrm{CaP}$ scaffold are affected by the content of fiber ${ }^{[12]}$. Petre et al. demonstrate that the fiber dispersion is a predominantly impact factor for the efficacy of fiber reinforcement due to the heterogeneous dispersion with a higher fiber amount ${ }^{[10]}$. It is reported that fibers with a shorter length are favorable for improving the fiber dispersity in composite ${ }^{[9]}$.

Additionally, CaP scaffold is generally fabricated via a variety of methods, including direct foaming ${ }^{[13]}$, gel-casting $^{[14]}$, phase separation ${ }^{[15]}$, etc. However, these methods are elusive to produce the precise shape and size for $\mathrm{CaP}$ scaffold to match various bone defects which vary greatly in different cases. Moreover, these methods are also difficult to control the porous structure, e. g. the size, shape and distribution of pore, to mimic the structure of host bone ${ }^{[16]}$. Fortunately, 3D printing technology is a promising approach to resolve the aforementioned issue due to its unique capabilities to produce the precise bone repair scaffolds to match various bone defects and simulate the structure of natural bone ${ }^{[17,18]}$. There are two major ways to generate $\mathrm{CaP}$ scaffolds using 3D printing technology, powder-based $3 \mathrm{D}$ printing and extrusion-based 3D printing ${ }^{[19-22]}$. By reason of simplicity, flexibility and cost performance, extrusion-based 3D printing technology has been frequently used to fabricate CaP scaffold ${ }^{[20,23-26]}$, in which the CaP pastes with certain viscosity could be extruded through a nozzle and deposited layer by layer. The injectability and formability of $\mathrm{CaP}$ paste are key performances for extrusion-based 3D printing. However, the nozzle blockage occurred frequently during the 3D printing process because of the severe filter-pressing effect due to the solid-liquid separation of the mixture of $\mathrm{CaP}$ particles and liquid phase ${ }^{[27]}$. Previous study has shown that the filling of electrospun fibers would compromise the fluidity and injectability of the $\mathrm{CaP}$ paste due to the heterogeneous dispersion of fibers ${ }^{[15]}$. The addition of fibers into $\mathrm{CaP}$ paste may further aggravate its filter-pressing effect. Therefore, it is still a challenging task for 3D printing of $\mathrm{CaP}$ paste loaded with fibers based on extrusion way to get toughen $\mathrm{CaP}$ scaffold.

In this study, non-aggregated polylactic-co-glycolic acid (PLGA) fibers were prepared by combination with frozen section technique and pluronic F127 (F127) chemical dispersant. CaP pastes containing well dispersed PLGA fibers were prepared and characterized. Furthermore, $\mathrm{CaP}$ pastes containing well dispersed PLGA fibers were utilized in extrusion-based 3D printing. The compressive testing was performed for $3 \mathrm{D}$ printing CaP scaffolds.

\section{Materials and methods}

\subsection{Non-aggregated PLGA fibers}

\subsubsection{Fabrication of non-aggregated PLGA fibers}

PLGA (LA (lactic acid): GA (glycolic acid) $=75$ : $25, \mathrm{Mw}$ (molecular weight $)=95000 \mathrm{Da})$ was obtained from Foliaplast Biological Technology Company (Changchun, China). The non-aggregated PLGA fibers were prepared via electrospinning combined with frozen section technology ${ }^{[28]}$. In brief, PLGA $(10 \mathrm{wt} \%)$ was dissolved overnight in a dichloromethane/DMF $(\mathrm{N}, \mathrm{N}-$ Dimethylformamide) mixture (3: $1, \mathrm{v} / \mathrm{v})$ by stirring to obtain a homogeneous solution. The solution was placed into a $10 \mathrm{~mL}$ syringes to be fitted with a 21 -gauge needle. Electrospinning parameters were as follows: the applied electric voltage to be $12 \mathrm{kV}$, the distance between the syringe needle and the grounded drum to be $15 \mathrm{~cm}$, and the solution feed rate to be $10 \mathrm{~mL} \cdot \mathrm{h}^{-1}$. All as-prepared PLGA electrospun fibers were dried at ambient temperature under vacuum for $24 \mathrm{~h}$. Subsequently, the PLGA electrospun fibers were immersed in the $5 \mathrm{wt} \% \mathrm{~F} 127$ (Sigma Aldrich, USA) solution for $3 \mathrm{~h}$, and folded in a direction perpendicular to the fiber orientation. Afterward, the folded electrospun fibers were placed at $-20{ }^{\circ} \mathrm{C}$ for freezing and then $100 \mu \mathrm{m}$ of successive sections were carried out with freezing microtome $(\mathrm{cm} 1860$, Leica, Germany). Finally, the electrospun fibers slices were ultrasonically dispersed in ethanol, collected by centrifugation and vacuum desiccation to obtain non-aggregated PLGA fibers.

\subsubsection{Characterization of non-aggregated PLGA fibers}

Scanning Electron Microscopy (SEM, JSM 7800F, Jeol, Japan) was performed to observe the morphology of PLGA electrospun fibers and non-aggregated PLGA fibers. They were fixed on copper stubs with conductive adhesive and coated with a layer of gold prior to subsequent observation. The diameter and the length distribution of non-aggregated PLGA fiber were measured 
by image pro plus 6.0 software based on SEM images.

The static contact angles were measured for the PLGA electrospun fiber membrane treated with and without F127 by the Contact Angle analyzer (DSA100, Kruss Gmbh, Germany) with deionized water.

\subsection{CaP pastes load with well dispersed PLGA fibers}

2.2.1 Preparation of $\mathrm{CaP}$ pastes loaded with well dispersed PLGA fibers

The CaP powder was mixed with $58 \% \alpha$-TCP, $25 \%$ $\mathrm{CaHPO}_{4} \cdot 2 \mathrm{H}_{2} \mathrm{O}, 8.5 \% \mathrm{CaCO}_{3}$ and $8.5 \%$ hydroxyapatite $(\mathrm{HA})^{[29]}$. Then, the mixture milled in absolute ethanol using Planetary ball mill (QM-1SP4, Qixin, China) at $400 \mathrm{r} \cdot \mathrm{min}^{-1}$ with polyamides jars $(500 \mathrm{~mL})$ for $10 \mathrm{~h}$. Finally, the mixture was dried and grinded to get the final $\mathrm{CaP}$ powder. Non-aggregated PLGA fibers of different weight content were added into liquid phase of $\mathrm{K}_{2} \mathrm{HPO}_{4}$ solution $(0.1 \mathrm{M})$ to prepare fiber dispersion solution by ultrasonic vibration. Then, the $\mathrm{CaP}$ powder and the fiber dispersion solution was mixed at a solid-liquid ratio of 0.9 to develop CaP pastes load with different weight contents of PLGA fiber, which were noted as $\mathrm{CaP}-\mathrm{X} \% \mathrm{~F}$ ( $X$ represented as the weight content of fiber in $\mathrm{CaP}$ pastes, $X=0 \mathrm{wt} \%, 1 \mathrm{wt} \%, 2 \mathrm{wt} \%, 3 \mathrm{wt} \%$ and $5 \mathrm{wt} \%$ ).

2.2.2 Characterization of $\mathrm{CaP}$ pastes loaded with well dispersed PLGA fibers

The injectability of $\mathrm{CaP}-\mathrm{X} \% \mathrm{~F}$ pastes was characterized by a Universal material testing machine (5567, Instron, USA). The tested $\mathrm{CaP}-\mathrm{X} \% \mathrm{~F}$ pastes consisted of $2 \mathrm{~g}$ of CaP powder and $1.8 \mathrm{~mL}$ of fiber dispersion solution $(0 \mathrm{wt} \%, 1 \mathrm{wt} \%, 3 \mathrm{wt} \%$ and $5 \mathrm{wt} \%)$, which were mixed into homogeneous paste and add to the $5 \mathrm{~mL}$ syringe, respectively. The vertical pressure was applied to the syringe using the universal testing machine at a compression rate of $15 \mathrm{~mm} \cdot \mathrm{min}^{-1}$, and the testing was stopped when the applied pressure was greater than $100 \mathrm{~N}^{[30]}$. The average extrusion force was determined by calculating the mean value of the extrusion force curve in the plateau zone as described in previous report ${ }^{[31]}$. Then the extruded percentage of $\mathrm{CaP}-\mathrm{X} \% \mathrm{~F}$ pastes was calculated by:

$$
\text { Extruded percentage }=\frac{w_{0}-w_{1}}{w_{0}-w} \times 100 \%,
$$

where $w_{0}$ and $w_{1}$ are the weight of syringe before and after injection testing, respectively. $w$ indicates the weight of the empty syringe.

The rheological behaviors of $\mathrm{CaP}-\mathrm{X} \% \mathrm{~F}$ pastes were measured on Rotational rheometer (DHR-1, TA, USA) fitted with a parallel plate configuration (diameter $20 \mathrm{~mm}$, gap $1 \mathrm{~mm}$ ) at a constant temperature. The shear rate sweep testing was implemented to determine the effect of shear rate on viscosity with shear rate change from $0.001 \mathrm{~s}^{-1}$ to $50 \mathrm{~s}^{-1}$.

The Gilmore needle test was used to characterize the setting time of $\mathrm{CaP}-\mathrm{X} \% \mathrm{~F}$ pastes ${ }^{[32]}$. The initial setting time (IT) and the final setting time (FT) were determined by applying the light needle (110 g) with a bigger diameter $(5 \mathrm{~mm})$ and the heavy needle $(300 \mathrm{~g})$ with a small diameter $(1.1 \mathrm{~mm})$, respectively. The mixed $\mathrm{CaP}-\mathrm{X} \% \mathrm{~F}$ paste was then filled into a mold, and the light needle was pressed vertically into the paste surface. Then the measurement was performed every $15 \mathrm{~s}$ until the surface of paste had no obvious traces, which the corresponding time was as the IT. Subsequently, the FT was measured by using the similar method with a heavy needle.

\subsection{D printing of CaP pastes loaded with well dis- persed PLGA fibers}

The $\mathrm{CaP}-\mathrm{X} \% \mathrm{~F}$ scaffolds were fabricated by a custom-built extrusion-based 3D printer in the same manner as previously ${ }^{[33]}$. The general procedure for the preparation of $3 \mathrm{D}$ printing $\mathrm{CaP}-\mathrm{X} \% \mathrm{~F}$ scaffolds was depicted in Fig. 1. In terms of injection test, pure $\mathrm{CaP}$ pastes and $\mathrm{CaP}-(1 \%, 2 \%, 3 \%) \mathrm{F}$ pastes were chosen to be used in extrusion-based 3D printing. The nozzle inner diameter was $500 \mu \mathrm{m}$ and the moving speed of the printing head was $4 \mathrm{~mm} \cdot \mathrm{s}^{-1}$. Finally, the $\mathrm{CaP}-X \% \mathrm{~F}$ scaffolds were cured in a $100 \%$ relative humidity at $37^{\circ} \mathrm{C}$ for $24 \mathrm{~h}$.

The 3D print model was designed by Soildworks 2014 software, then imported into the Simplify 3D software and saved as a stereolitography (.stl) file after slicing, and finally imported into the extruded 3D printing system.

\subsection{Characterization of 3D printing of toughened CaP scaffold}

The shape fidelity of $\mathrm{CaP}-\mathrm{X} \% \mathrm{~F}$ scaffolds was 


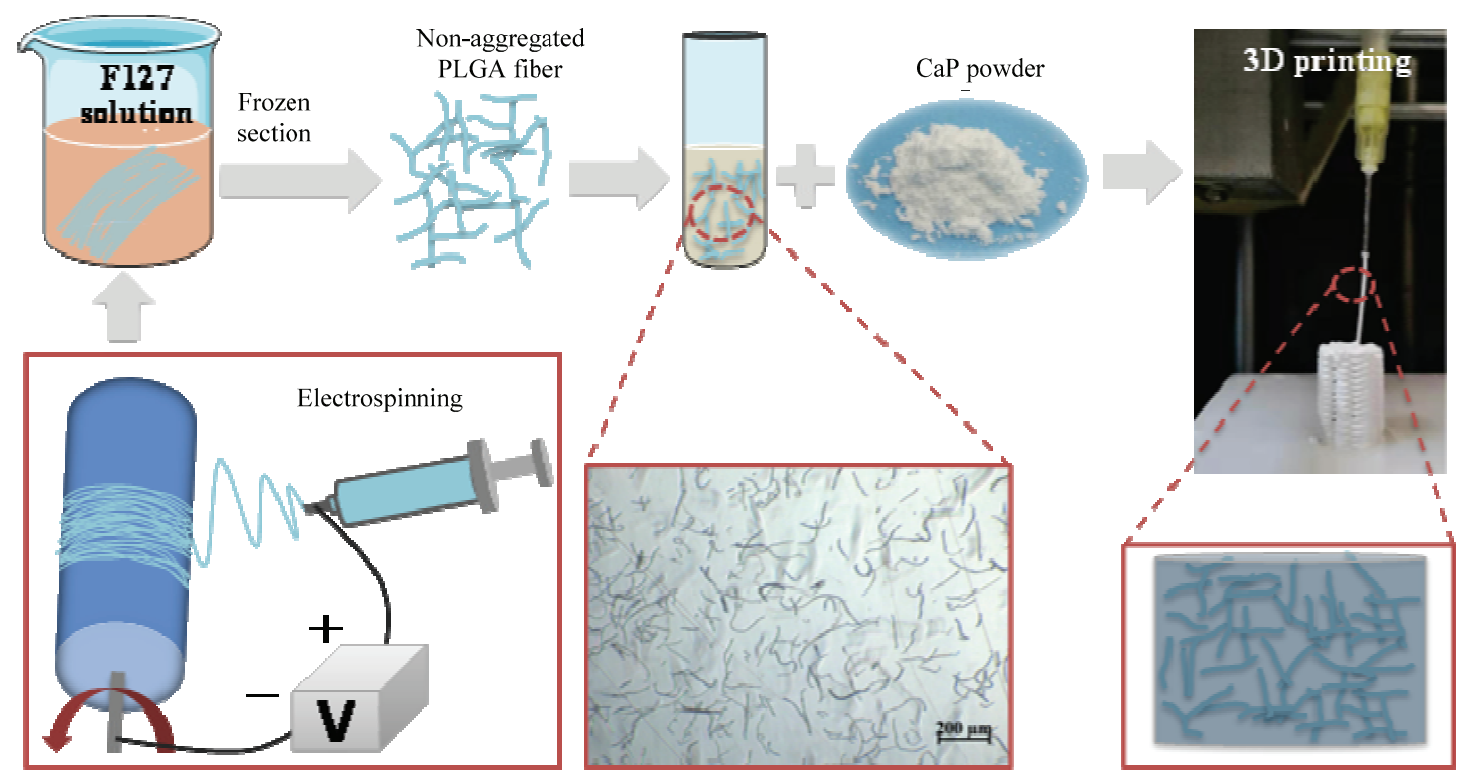

Fig. 1 Schematic diagram of the fabrication process of $\mathrm{CaP}$ pastes containing PLGA fiber and 3D printing.

characterized by measuring the height and diameter of the scaffold with different printed layers. The surface morphology of $\mathrm{CaP}-\mathrm{X} \% \mathrm{~F}$ scaffolds was characterized by a stereo microscope (SZX16, Olympus, Japan). The diameter of print line was measured by Image pro plus 6.0 software based on stereoscopic images. The phase compositions of $\mathrm{CaP}-\mathrm{X} \% \mathrm{~F}$ scaffolds and pure HA were analyzed by $X$-ray diffraction (XRD, Empyrean, Philips, Netherlands). Diffraction patterns were scanned at $2 \theta$ ranges from $4^{\circ}$ to $80^{\circ}$ in stepscan intervals of $0.02^{\circ}$, and $\mathrm{Cu} \mathrm{K} \alpha$ radiations were $40 \mathrm{kV}$ and $40 \mathrm{~mA}$. The content of $\mathrm{HA}$ and crystallinity of the $\mathrm{CaP}-\mathrm{X} \% \mathrm{~F}$ scaffolds were calculated by Jade 6.0 software based on XRD patterns. The content of HA was calculated by ${ }^{[34]}$ :

$$
\text { HA content } \%=\frac{I_{\mathrm{HA}}}{I_{\mathrm{SUM}}} \times 100 \% \text {, }
$$

where $I_{\mathrm{HA}}$ is the intensity of diffraction primary maximum of the HA phase, $I_{\mathrm{SUM}}$ is the sum of the diffraction primary maximum of other phases.

Cylindrical $\mathrm{CaP}-X \% \mathrm{~F}$ scaffolds with $10 \mathrm{~mm}$ in diameter and $15 \mathrm{~mm}$ in height were prepared by extrusion-based 3D printer for compressive testing. A Universal testing machine (5567, Instron, USA) was employed for compressive testing at the loading rate of $0.5 \mathrm{~mm} \cdot \mathrm{min}^{-1}$. The compressive toughness was deter- mined by calculating the integration area of the compressive stress-strain curve at the peak stress ${ }^{[35]}$.

The compressive fractured sections of $\mathrm{CaP}-\mathrm{X} \% \mathrm{~F}$ scaffolds were characterized by SEM (SU4800, HITACHI, Japan) after being coated by a layer of gold. The surfaces roughness of $\mathrm{CaP}-\mathrm{X} \% \mathrm{~F}$ scaffolds were characterized by white light interferometer (Contour GT-X, Bruker, Germany).

\subsection{Characterization of cell proliferation and alka- line phosphatase (ALP) activity}

The biocompatibility was investigated by culturing human osteoblastic cells (MG-63) on the CaP-X\%F scaffold. The cells were kindly provided by the National Engineering Center for Biomaterials, Sichuan University, Chengdu, China. Sterilized 3D printed $\mathrm{CaP}-\mathrm{X} \% \mathrm{~F}$ scaffold were co-cultured with MG-63 cells at the cell density of $2 \times 10^{4}$ cells $\cdot \mathrm{mL}^{-1}$ in a 24 -well plate with Dulbecco's Modified Eagle's Medium (DMEM, Gibco, USA) supplemented with 10\% Fetal Bovine Serum (FBS, ExCell, China), 1\% penicillin (Sigma-Aldrich, USA) and streptomycin (Sigma-Aldrich, USA) at $37{ }^{\circ} \mathrm{C}$ and $5 \% \mathrm{CO}_{2}$. The viability of MG-63 cells in different scaffold was examined by Alamar-blue reagent (Invitrogen, USA). After $1 \mathrm{~d}, 3 \mathrm{~d}, 5 \mathrm{~d}$ and $7 \mathrm{~d}$ of culture, $1 \mathrm{~mL}$ of working solution of $10 \%$ Alamar-blue reagent was 
added to each well. Then, the 24-well plate was incubated at $37{ }^{\circ} \mathrm{C}$ and removes $200 \mu \mathrm{L}$ of solution into 96-well plate after $4 \mathrm{~h}$. The absorbance value of each well was measured at $570 \mathrm{~nm}$ and $600 \mathrm{~nm}$ respectively with a microplate reader ( $\mu$ Quant, Bio-Tek, USA).

The ALP activity was assessed to characterize the effect of $\mathrm{CaP}-X \% \mathrm{~F}$ scaffold on osteogenic differentiation ability of MG-63 cells. At day 14, the medium were removed and each well was washed with Phosphate Buffer Solution (PBS) followed by the addition of lysate, and then subjected the 24-well plate to a temperature of $4{ }^{\circ} \mathrm{C}$ for $30 \mathrm{~min}$. Subsequently, the cell lysate was centrifuged for $15 \mathrm{~min}$ at $12000 \mathrm{rpm}$. According to the protocol of the protein assay kit (Boster, China), a volume of $25 \mu \mathrm{L}$ supernatant was removed and mixed with the $200 \mu \mathrm{L}$ working solution in 96-well plate to incubate for $30 \mathrm{~min}$ at $37{ }^{\circ} \mathrm{C}$. The absorbance value of each well was measured at $625 \mathrm{~nm}$ with a microplate reader to obtain the total protein content. According to the protocol of the ALP assay kit (Najing Jiancheng Bioengineering Institute, China), $50 \mu \mathrm{L}$ supernatant was mixed with $100 \mu \mathrm{L}$ working solution and then add $30 \mu \mathrm{L}$ coloration liquid into each well after incubated for $15 \mathrm{~min}$ at $37^{\circ} \mathrm{C}$. Then, the absorbance value of each well was measured at $520 \mathrm{~nm}$ to calculate the total ALP content. Finally, the ALP activity was calculated by dividing the total ALP content by the total protein content $^{[20]}$.

\subsection{Characterization of morphology of cell on CaP- $X \% \mathrm{~F}$ scaffolds}

The $\mathrm{CaP}-X \% \mathrm{~F}$ scaffolds were washed with PBS and fixed in $2.5 \%$ glutaraldehyde solution for $24 \mathrm{~h}$ after co-cultured with cells for $3 \mathrm{~d}$. Then, the scaffolds were dehydrated using graded ethanol $(30 \%, 50 \%, 70 \%, 80 \%$, $90 \%$ and $100 \%)$. Finally, the $\mathrm{CaP}-\mathrm{X} \% \mathrm{~F}$ scaffolds were dried by critical point drying and coated with a layer of gold for SEM observation.

$\mathrm{CaP}-\mathrm{X} \% \mathrm{~F}$ scaffolds were washed with $\mathrm{PBS}$, and dyed by $2 \mathrm{mM}$ calcein-AM (US Everbright Inc, China) at $37{ }^{\circ} \mathrm{C}$ for $30 \mathrm{~min}$ after co-cultured with cell for $3 \mathrm{~d}$. Immediately, cell on $\mathrm{CaP}-\mathrm{X} \% \mathrm{~F}$ scaffolds was observed by fluorescence microscope (BX63, Olympus, Japan) prior to washing with PBS.

\subsection{Statistical analysis}

All quantitative data were tested triple and expressed as mean \pm Standard Deviation (SD). Statistical analysis was performed using student's paired $t$-test and ANOVA. Significant differences were assumed at $p<$ 0.05 .

\section{Results and discussion}

\subsection{Characterization of non-aggregated PLGA fibers}

The main purpose of this study was to develop a $\mathrm{CaP}$ paste comprising well dispersed fibers for extrusion-based 3D printing to construct toughened $\mathrm{CaP}$ scaffolds. Therefore, it was necessary to prepare non-aggregated PLGA fibers firstly to ensure their well dispersion in $\mathrm{CaP}$ paste. As a result, the injectability of this paste could be maintained to match the requirement of extrusion-based 3D printing.

In this study, non-aggregated PLGA fibers were obtained by frozen sections combined with F127 chemical dispersants (Fig. 2). The surface of PLGA electrospun fibers was smooth, indicating that the PLGA solution had good fluidity during the electrospinning process. The average diameter of the PLGA electrospun fibers was $4.2 \mu \mathrm{m} \pm 1.3 \mu \mathrm{m}$ (Fig. 2a). Fig. $2 \mathrm{~b}$ shows the micromorphology of the non-aggregated PLGA fibers, in which no intertwinement was observed among the PLGA fibers. The lengths of the PLGA fibers were in the range of $48.7 \mu \mathrm{m}-229.4 \mu \mathrm{m}$. Most PLGA fibers were curved, and a few fiber ends were crimped.

The surfactant F127 with good biocompatibility has been used as the chemical dispersant to improve the surface wettability of the PLGA fiber ${ }^{[36,37]}$. The change in contact angle of PLGA electrospun fiber membrane is shown in Fig. 2c. The surface of the PLGA electrospun fiber membrane was hydrophobic, while the contact angle was reduced from $120.3^{\circ} \pm 3.8^{\circ}$ to $94.1^{\circ} \pm 10.3^{\circ}$ after treatment with F127, indicating that F127 significantly reduced its hydrophobicity. F127 comprises hydrophobic group polypropylene oxide (PPO) and hydrophilic group polyethylene oxide (PEO). As shown in Fig. 2d, it was hypothesized that the hydrophilic group, PEO, was prone to exposing to the outside when F127 was adsorbed on the hydrophobic surface of PLGA fibers than PPO did, which dramatically decreased the hydrophobicity of the PLGA electrospun fibers, similar 

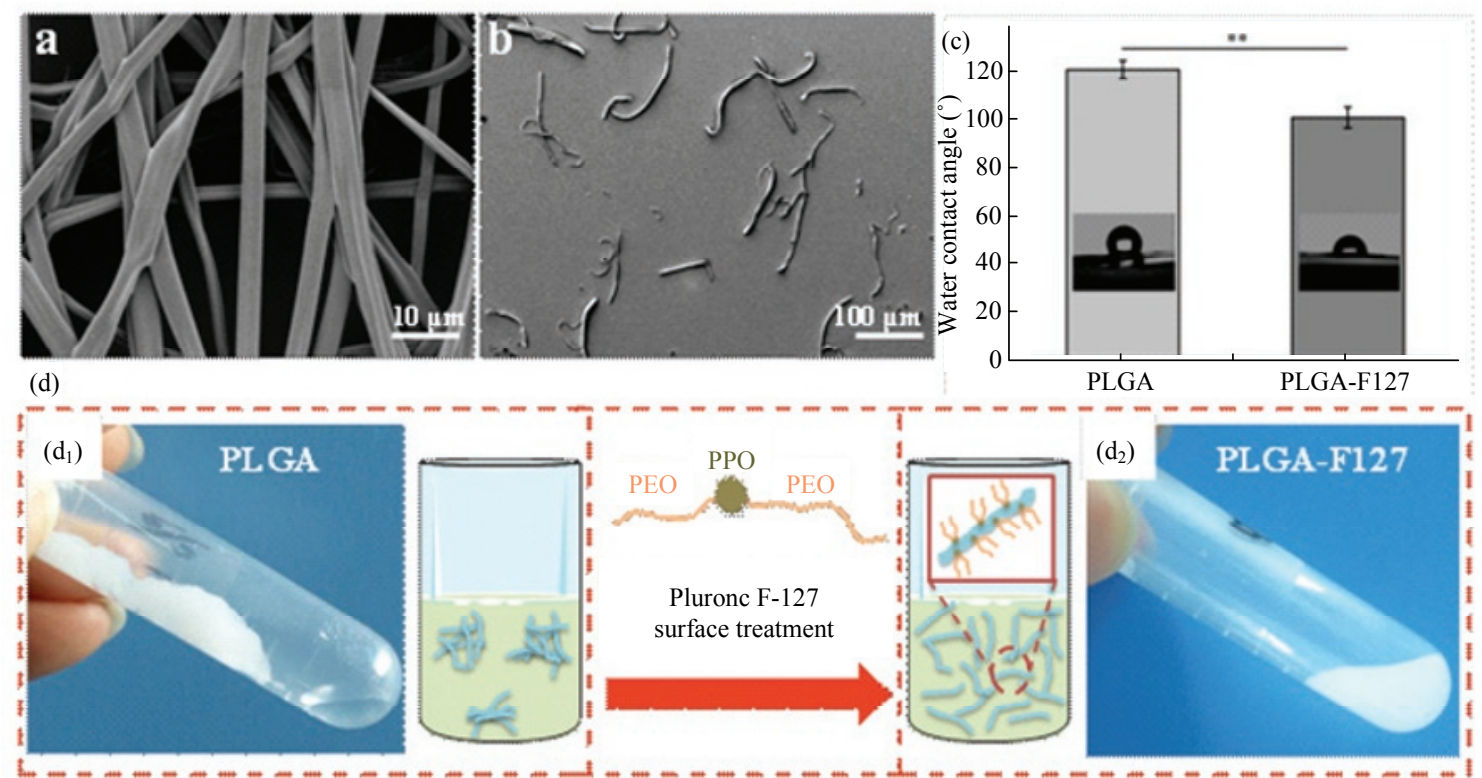

Fig. 2 SEM micrographs of directional PLGA electrospun fibers (a) and non-aggregated PLGA fibers obtained by frozen section (b). Variation in the contact angle of PLGA electrospun fiber membranes before and after treatment with F127 (c). Photographs and schematic diagrams of PLGA fibers dispersed in the liquid phase before and after treatment with $\mathrm{F} 127(\mathrm{~d}), \mathrm{d}_{1}$ and $\mathrm{d}_{2}$ show the dispersion profiles of PLGA fibers in the liquid phase before and after infiltration treatment with F127, respectively $\left({ }^{*} p<0.05, *^{*} p<0.01, n=3\right)$.

to that observed in previous report ${ }^{[38]}$. The increased surface wettability of PLGA fibers significantly improved the dispersion of PLGA fibers in the liquid phase (Fig. $2 \mathrm{~d}_{2}$ ). In contrast, PLGA fibers without F127 treatment tended to agglomerate in liquid phase, thus failing to form a homogeneous PLGA fiber dispersion solution (Fig. 2d $\mathrm{d}_{1}$ ). The similar chemical dispersant studies also have been employed to improve the dispersion of nanoparticles with a hydrophobic surface in the liquid phase ${ }^{[39,40]}$. Maenz et al. found that the generally decreased contact angles of the PLGA fibers after oxygen plasma treatment may allow a better wetting of the fibers with Calcium Phosphate Cement (CPC) paste, which was beneficial for improving of the mechanical properties of fiber toughened $\mathrm{CaP}^{[11]}$.

\subsection{Characterization of CaP pastes loaded with well dispersed PLGA fibers}

The injectability of $\mathrm{CaP}$ pastes containing PLGA fibers is shown in Fig. 3. The extruded percentage of $\mathrm{CaP}$ pastes containing PLGA fibers were still more than $90 \%$ when the contents of PLGA fiber were no more than $3 \mathrm{wt} \%$, whereas the extruded percentage was decreased significantly to $47 \%$ when the content of PLGA fiber was $5 \mathrm{wt} \%$. The average extrusion forces of four types of $\mathrm{CaP}$ pastes were $3.47 \mathrm{~N} \pm 0.19 \mathrm{~N}, 5.81 \mathrm{~N} \pm$ $0.73 \mathrm{~N}, 7.42 \mathrm{~N} \pm 0.96 \mathrm{~N}$, and $18.17 \mathrm{~N} \pm 10.74 \mathrm{~N}$ for pure $\mathrm{CaP}$ pastes and $\mathrm{CaP}$ pastes with fiber contents of $1 \mathrm{wt} \%$, $3 \mathrm{wt} \%$, and $5 \mathrm{wt} \%$, respectively. Moreover, the typical extrusion force curve revealed that the relatively low and stable extrusion forces for the pure $\mathrm{CaP}$ paste and $\mathrm{CaP}$ pastes with fiber contents of $1 \mathrm{wt} \%$ and $3 \mathrm{wt} \%$ (Fig. 3a). On the contrary, the extrusion force curve of $\mathrm{CaP}-5 \% \mathrm{~F}$ shows fluctuated accompanying with the sharply increased extrusion force, which corresponded to the severe blockage of syringe. As the extrusion force increased, the blocked $\mathrm{CaP}$ paste in syringe exit was squeezed out, which resulted in the decreasing of extrusion force. This cycle repeated eventually leading to blockage of syringe. The average extrusion force of $\mathrm{CaP}$ pastes increased with the increasing of the content of PLGA fibers, which indicated the more aggravated filter-pressing effect of $\mathrm{CaP}$ paste with more content of fibers. Generally, the length of PLGA fibers was much larger than that of $\mathrm{CaP}$ particle size, which might intertwine and reduce the injectability of $\mathrm{CaP}$ paste ${ }^{[41]}$. Maenz et al. reported that the injectability of CPC with fiber decreased significantly with increasing of length and the content of PLGA fibers ${ }^{[12]}$. However, the dispersion of fiber in matrix also affects the injectability of 

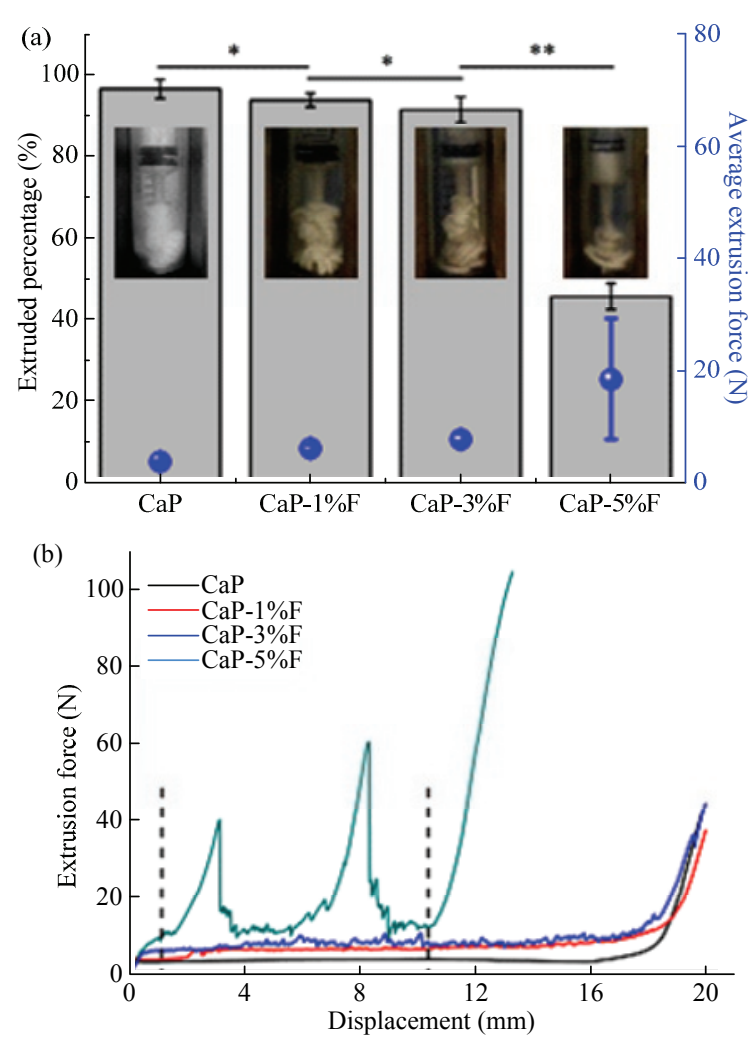

Fig. 3 Injectability of $\mathrm{CaP}$ pastes with different fiber contents. Extruded percentage, average extrusion force (a) and typical extrusion force curves (b) of $\mathrm{CaP}$ pastes with different fiber contents. The average extrusion force is the mean value of the extrusion force curve in dotted line area. $\left({ }^{*} p<0.05,{ }^{* *} p<0.01, n=3\right)$.

$\mathrm{CaP}$ paste. The appropriate length and content of fibers still might sustain the higher injectability, which is owing to the well dispersion of PLGA fibers in $\mathrm{CPC}^{[12]}$. Similarly, $\mathrm{CaP}-1 \% \mathrm{~F}$ and $\mathrm{CaP}-3 \% \mathrm{~F}$ showed the relatively higher extruded percentage, which showed the lower average extrusion forces and indicated the well dispersion of PLGA fiber. Thus CaP-5\%F was not suitable for extrusion-based 3D printing due to its poor injectability. Consequently, $\mathrm{CaP}$ pastes with fiber contents of $1 \mathrm{wt} \%$, $2 \mathrm{wt} \%$, and $3 \mathrm{wt} \%$ were used to in follow-up experiments.

The rheological properties of $\mathrm{CaP}$ pastes containing PLGA fibers are shown in Fig. 4a. Previous research confirmed that $\mathrm{CaP}$ pastes is a kind of pseudoplastic fluid with shear thinning behavior ${ }^{[42]}$. The reduced tendency of viscosity was observed with the increasing of shear rate for four $\mathrm{CaP}$ pastes in Fig. 4a. However, it appeared a distinct erratic viscosity value in the middle of rheological curves, which was hypothesized to be associated with self-setting reaction. As described in the insert diagram in Fig. 4a, the initial viscosities of $\mathrm{CaP}$ pastes with different fiber contents were in the following order: $\mathrm{CaP}-3 \% \mathrm{~F}>\mathrm{CaP}>\mathrm{CaP}-2 \% \mathrm{~F}>\mathrm{CaP}-1 \% \mathrm{~F}$. It revealed that the viscosity and shear thinning behavior of $\mathrm{CaP}$ pastes did not be altered significantly with the increasing of fiber content. This was different from the previous study, which the viscosity of the fresh composite pastes would increase with the increasing fiber content ${ }^{[43]}$. It was conjectured to be due to the effect of PLGA fibers treated with F127 as the description of Parveen et al. ${ }^{[44]}$. F127 has PEO side chains, which are responsible for the improvement of the fluidity and dispersion of cement particles similar to the polycarboxylate-based plasticizers ${ }^{[4]}$. Therefore, the initial viscosity of the $\mathrm{CaP}$ pastes with fibers was depended on the impact of fiber and F127. Nevertheless, this shear thinning feature of $\mathrm{CaP}$ paste with PLGA fibers might be conducive to extrusion-based $3 \mathrm{D}$ printing.

The setting time of $\mathrm{CaP}$ pastes containing PLGA fibers is shown in Fig. 4b. The initial and final setting times of $\mathrm{CaP}$ pastes containing PLGA fibers both decreased significantly with the addition of PLGA fibers compared to those of pure $\mathrm{CaP}$ paste. Moreover, the setting time of $\mathrm{CaP}$ pastes gradually decreased with an increasing content of PLGA fiber, which might be explained by the good surface wettability of the PLGA fibers treated with F127. Similarly, previous study also found that the setting time of CPC decreased with the addition of fiber fillers ${ }^{[7,45]}$. The initial setting time of $\mathrm{CaP}$ pastes containing PLGA fibers was approximately 6 min, which indicated the loss of flow and plasticity for $\mathrm{CaP}$ paste. The final setting time of $\mathrm{CaP}$ pastes containing PLGA fibers was approximately $10 \mathrm{~min}$, which exhibited the completely solidified with a certain mechanical properties to tolerate the pressure exerted by a heavy Gillmore needle ${ }^{[32]}$. In fact, the setting time reflected the solidification reaction among constituents of $\mathrm{CaP}$ paste. The $\mathrm{CaP}$ powder formulation used in this study was derived from Biocement $\mathrm{D}$ of calcium phosphate bone cement ${ }^{[29]}$. A series of dissolution and precipitation reactions occurred among $\alpha$-TCP, $\mathrm{CaHPO}_{4} \cdot \mathrm{H}_{2} \mathrm{O}$, and $\mathrm{CaCO}_{3}$ with higher solubility, which resulted in the formation of thermodynamic stable HA and solidification of the $\mathrm{CaP}$ paste when liquid phase containing PLGA fibers were mixed with CaP powder ${ }^{[29]}$. In addi- 
tion, the setting time plays an important key for the formability of $\mathrm{CaP}$ pastes containing PLGA fibers in extrusion-based 3D printing. The present setting time of PLGA toughened $\mathrm{CaP}$ pastes is a bit short for extrusion printing process, in particular, for printing $\mathrm{CaP}$ scaffold with large size and requiring more than 10 minutes of printing time. It is found the lower ambient temperature could prolong the setting time of $\mathrm{CaP}$ paste in our and the other previous studies ${ }^{[46]}$. Hence, it is possible to get the longer printing time by decreasing the ambient temperature when printing. In addition, it is feasible to add biocompatible retarder, e.g. thinning citric acid, into $\mathrm{CaP}$ paste to extend the setting time of $\mathrm{CaP}$ paste and increase the printing time. Moreover, the shear thinning property of $\mathrm{CaP}$ pastes is favor of increasing the printing time of $\mathrm{CaP}$ paste due to the shearing force during extrusion process.

Several studies have confirmed calcium phosphate bone cement with good injectability and formability in extrusion-based 3D printing research ${ }^{[47-49]}$. The advantage of calcium phosphate bone cement used as 3D printed paste was the mild printing and cured conditions, e.g. avoiding of high temperature sintering. Therefore, it was adapted to loading drugs and biological factors in $\mathrm{CaP}$ paste to avoid inactivated. Based on the present results, $\mathrm{CaP}$ pastes with PLGA fibers no more than $3 \mathrm{wt} \%$ might had the good injectability, appropriate rheological properties and setting time for extrusion-based 3D printing, which was owing to the well dispersion of PLGA fibers in CaP pastes.

\subsection{D printing of toughened CaP scaffold}

Fig. 5 shows the 3D printing performance of $\mathrm{CaP}$ pastes with different contents of PLGA fibers. All four $\mathrm{CaP}$ pastes could be extruded continuously over a long time through needles of $500 \mu \mathrm{m}$ diameters owing to the good injectability and appropriate rheological property (Fig. 5a). Moreover, complex structures, e. g. hemispherical, hollow cylindrical, solid cylindrical, and square scaffolds, could be printed by extrusion-based 3D printer (Fig. 5b).

Shape fidelity is an important index for evaluating the formability of $\mathrm{CaP}$ pastes. The shape fidelity of 3D printed $\mathrm{CaP}$ scaffolds was assessed as the height (Fig. $5 \mathrm{c}_{1}$ ) and diameter (Fig. $5 \mathrm{c}_{2}$ ) compared to the de- signed size. The heights and diameters of 3D printing scaffolds were close to the designed size labelled as the line in Figs. $5 c_{1}$ and $5 c_{2}$ when was printed at various layers. Moreover, there was no collapse occurrence during printing process owing to the appropriate viscosity and setting time of $\mathrm{CaP}$ pastes with different fiber contents. Fig. 6 shows the 3D printing cylindrical structure $(10 \mathrm{~mm} \times 15 \mathrm{~mm})$ with clear lines and pore structures. The average widths of the printed lines were $713.2 \mu \mathrm{m} \pm 14.7 \mu \mathrm{m}, 742.5 \mu \mathrm{m} \pm 45.8 \mu \mathrm{m}, 726.73 \mu \mathrm{m} \pm$ $16.7 \mu \mathrm{m}$, and $737.8 \mu \mathrm{m} \pm 26.1 \mu \mathrm{m}$ for $\mathrm{CaP}, \mathrm{CaP}-1 \% \mathrm{~F}$, $\mathrm{CaP}-2 \% \mathrm{~F}$, and $\mathrm{CaP}-3 \% \mathrm{~F}$, respectively. However, the diameter of printing line becomes wider than that of syringe needle, in which is $500 \mu \mathrm{m}$. As a result, the size and shape of pores in scaffolds changed compared to that of designed 3D model. Moreover, the pore deformation in different positions of $\mathrm{CaP}$ scaffolds is various as shown in Fig. 6. In addition, the line widths of the four

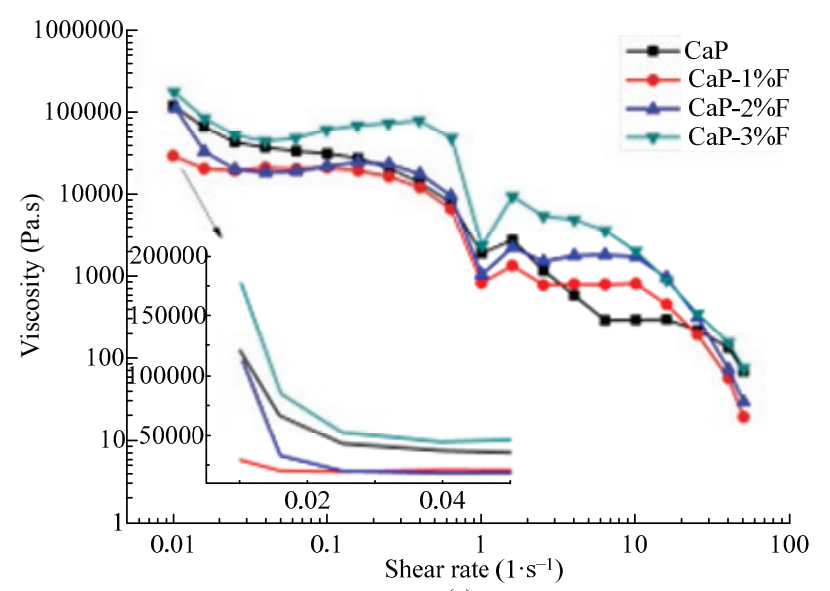

(a)

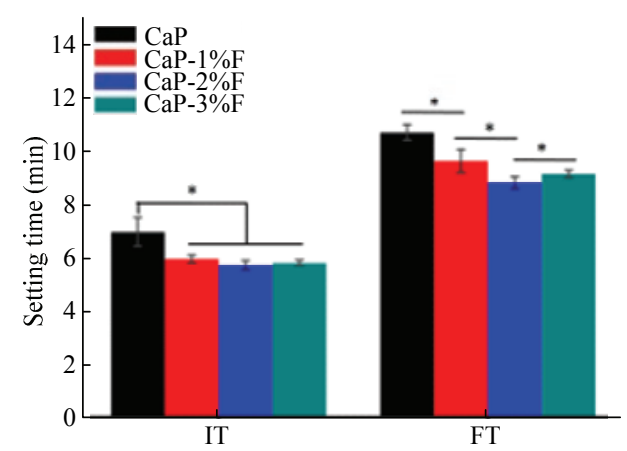

(b)

Fig. 4 Apparent viscosity as a function of shear rate for $\mathrm{CaP}$ pastes with different fiber contents. (a) Inset shows the initial viscosity change in the paste. Initial setting time and final setting time of CaP pastes with different fiber contents (b) $\left({ }^{*} p<0.05\right.$, ** $p$ $<0.01, n=3)$. 
(a)
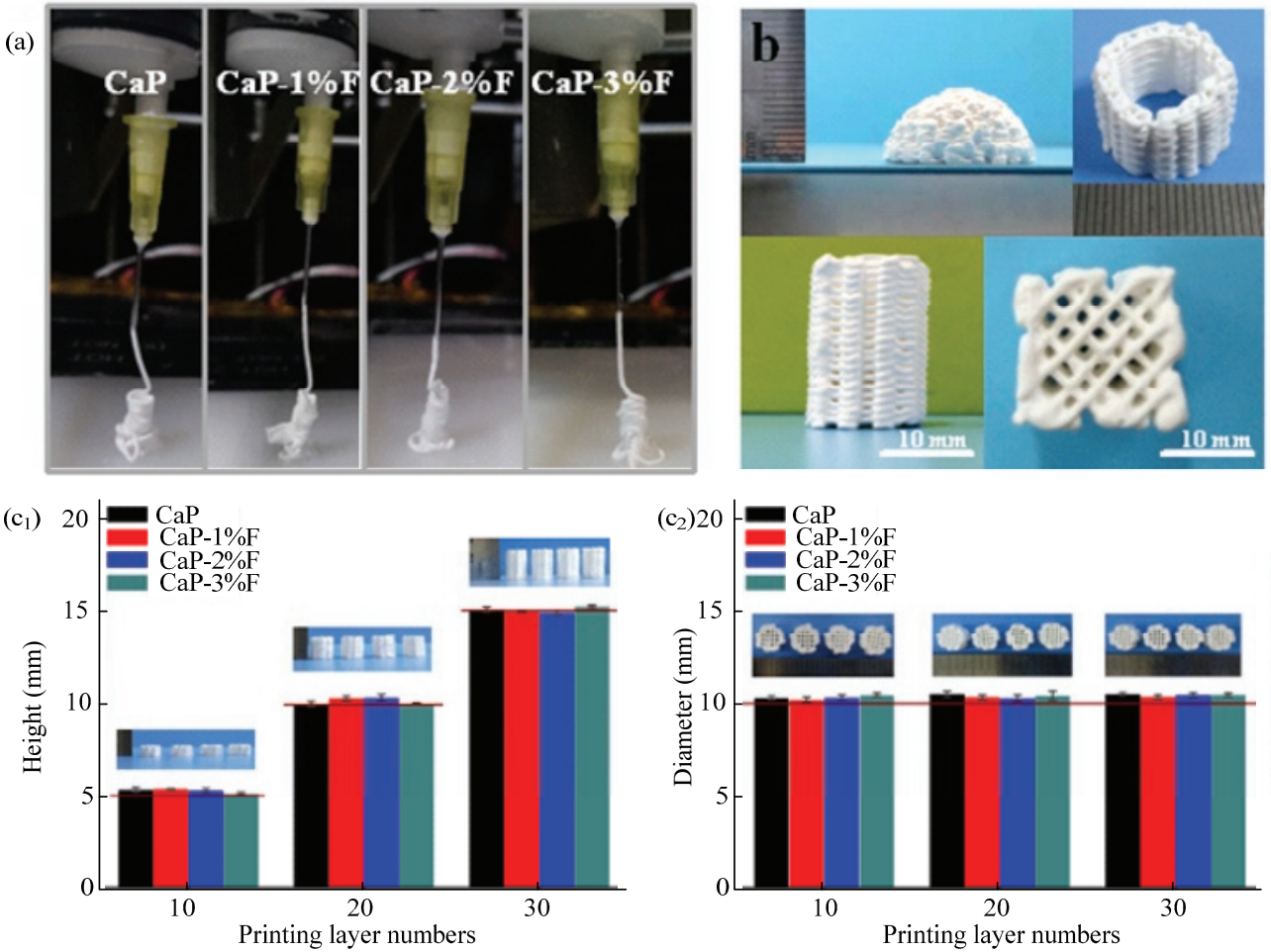

Fig. 5 3D printing of $\mathrm{CaP}$ pastes with different fiber contents. Photographs showing $\mathrm{CaP}$ pastes with different fiber contents continuously extruded from the needle with a nozzle diameter of $500 \mu \mathrm{m}$ (a). $\mathrm{CaP}-X \% \mathrm{~F}$ scaffolds of different shapes produced by $3 \mathrm{D}$ printing (b). The shape fidelity of CaP pastes with different fiber contents was assessed as the height $\left(\mathrm{c}_{1}\right)$ and diameter $\left(\mathrm{c}_{2}\right)$ of the CaP- $X \% \mathrm{~F}$ scaffolds when printing different layers (red line in the figure indicates the designed size).
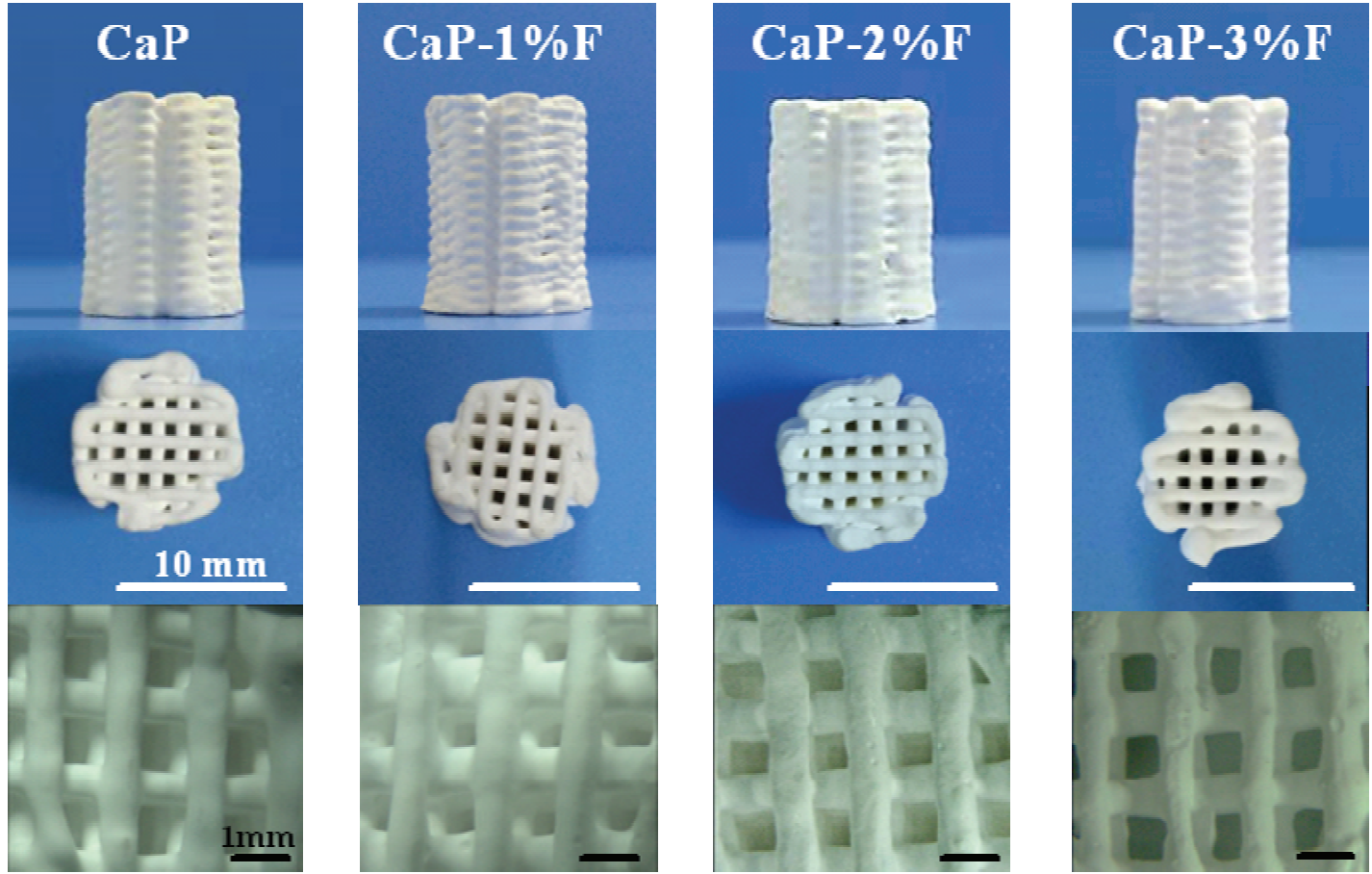

Fig. 6 The cylindrical structure and corresponding stereomicroscopic images of CaP scaffolds with different fiber contents which were printed using an extrusion-based 3D printer (inner needle diameter $500 \mu \mathrm{m}$, flow rate $0.006 \mathrm{~mL} \cdot \mathrm{s}^{-1}$ ). 
scaffolds did not change obviously, which indicated the addition of PLGA fibers did not affect the printing accuracy of $\mathrm{CaP}$ pastes.

\subsection{Phase composition of toughened CaP scaffold}

The phase compositions of $\mathrm{CaP}-X \% \mathrm{~F}$ scaffolds and pure HA are determined by XRD as shown in Fig. 7. High-intensity diffraction peaks XRD pattern appeared near $25.9^{\circ}, 31.7^{\circ}, 32.9^{\circ}, 34.0^{\circ}, 39.8^{\circ}, 46.7^{\circ}, 49.5^{\circ}$, and $50.5^{\circ}$ for four types of $\mathrm{CaP}$ scaffolds, which were consistent with the diffraction peaks of HA according to the standard card (PDF\#09-0432). It confirmed that the main component of the final hydration product was HA for CaP scaffolds. The contents of HA were $99.74 \%$, $99.77 \%, 99.63 \%$, and $99.67 \%$ in the $\mathrm{CaP}, \mathrm{CaP}-1 \% \mathrm{~F}$, $\mathrm{CaP}-2 \% \mathrm{~F}$, and $\mathrm{CaP}-3 \% \mathrm{~F}$ scaffolds, which were calculated as our previous study ${ }^{[34]}$, respectively. Additionally, the broad diffraction peak appeared at $31.7^{\circ}$, which indicated the final hydration product to be the poorly crystallized HA. The crystallinity values of the $\mathrm{CaP}$, $\mathrm{CaP}-1 \% \mathrm{~F}, \mathrm{CaP}-2 \% \mathrm{~F}$, and $\mathrm{CaP}-3 \% \mathrm{~F}$ scaffolds were calculated as $71.24 \%, 74.15 \%, 73.69 \%$, and $71.65 \%$, respectively. Previous studies found that the crystallinity of $\mathrm{CaP}$ in natural bone was relatively low, and $\mathrm{HA}$ with poor crystallinity showed higher biological activity and degradability ${ }^{[50]}$.

\subsection{Mechanical properties of 3D printed scaffold and morphology analysis}

The compressive mechanical properties of 3D printed $\mathrm{CaP}-\mathrm{X} \% \mathrm{~F}$ scaffolds are shown in Fig. 8. The stress of $\mathrm{CaP}$ scaffolds with PLGA fibers decreased slowly with the increasing of compression displacement and maintained a relatively stable stress value whereas the stress of pure $\mathrm{CaP}$ scaffolds decreased rapidly after peak loading as shown in the typical stress-strain curves for four types of CaP scaffolds (Fig. 8a). Additionally, the post-peak residual strength increased with the increasing of fiber contents. Especially, the CaP-3\%F scaffolds still kept about $80 \%$ of compressive stress after peak loading. These results indicated that the incorporation of PLGA fibers enhanced the load bearing capacity of CaP scaffolds by means of the improvement of toughness. Nevertheless, the compressive strength of pure $\mathrm{CaP}$ and $\mathrm{CaP}-(1 \%, 2 \%, 3 \%) \mathrm{F}$ scaffolds were $3.92 \mathrm{MPa} \pm 1.04 \mathrm{MPa}, 4.07 \mathrm{MPa} \pm 1.01 \mathrm{MPa}, 3.97 \mathrm{MPa}$ $\pm 0.54 \mathrm{MPa}, 4.01 \mathrm{MPa} \pm 0.47 \mathrm{MPa}$, respectively, without significant differences (Fig. 8b). The compressive strength of CaP scaffolds was not improved by the addition of PLGA fibers as shown in Fig. 8b as similar to the compressive strength of $3 \mathrm{D}$ printed scaffolds fabricated by self-curing $\mathrm{CaP}$ pastes ${ }^{[48,51]}$. Also the present compressive strength was lower than that of 3D printed $\mathrm{CaP}$ scaffolds after high temperature sintering ${ }^{[52]}$. Additionally, the compressive toughness and strain of $\mathrm{CaP}-(1 \%, 2 \%, 3 \%) \mathrm{F}$ scaffolds were higher than those of $\mathrm{CaP}$ scaffold at maximum compressive strength (Figs. $8 \mathrm{c}$ and $8 \mathrm{~d}$ ). Fig. $8 \mathrm{e}$ shows the images of $\mathrm{CaP}-\mathrm{X} \% \mathrm{~F}$ scaffolds after compressive testing. CaP- $(1 \%, 2 \%, 3 \%) \mathrm{F}$ scaffolds showed relative structural integrity with slightly deformation and some crevices, whereas the $\mathrm{CaP}$ scaffold was completely crushed into fragments. This phenomenon was owned to the crack resistance effect of PLGA fibers in the process of compression testing as similar results ${ }^{[33-55]}$. It potentially facilitated $\mathrm{CaP}-\mathrm{X} \% \mathrm{~F}$ scaffolds to be applied in clinic due to its ability of maintaining the shape of bone substitute although cracks might occur.

The major application of $\mathrm{CaP}$ scaffold is to fill bone defects. However, the limitation in clinical is the inherent brittleness of $\mathrm{CaP}$ scaffolds, particularly at load-bearing sites. Thus the toughness of $\mathrm{CaP}$ scaffolds was improved by incorporating PLGA fibers with high flexibility. The compressive strength of cancellous bone ranges from $0.1 \mathrm{MPa}$ to $27.3 \mathrm{MPa}^{[56]}$. The distribution range of the compressive strength of $\mathrm{CaP}$ scaffolds with PLGA fibers ranged from 3.97 MPa to 5.19 MPa,

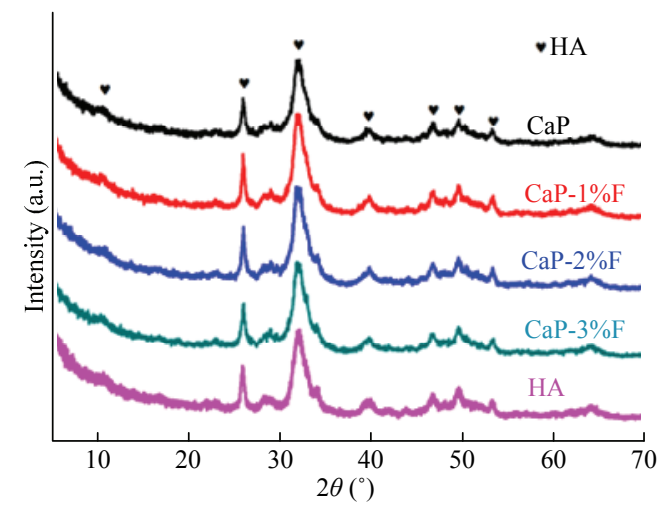

Fig. 7 Phase composition of 3D printed CaP scaffolds with different fiber contents after $24 \mathrm{~h}$ hydration at $37{ }^{\circ} \mathrm{C}$ and $100 \%$ humidity. The diffraction pattern of pure $\mathrm{HA}$ is used for comparison to determine the phase composition of $\mathrm{CaP}$ scaffolds. 

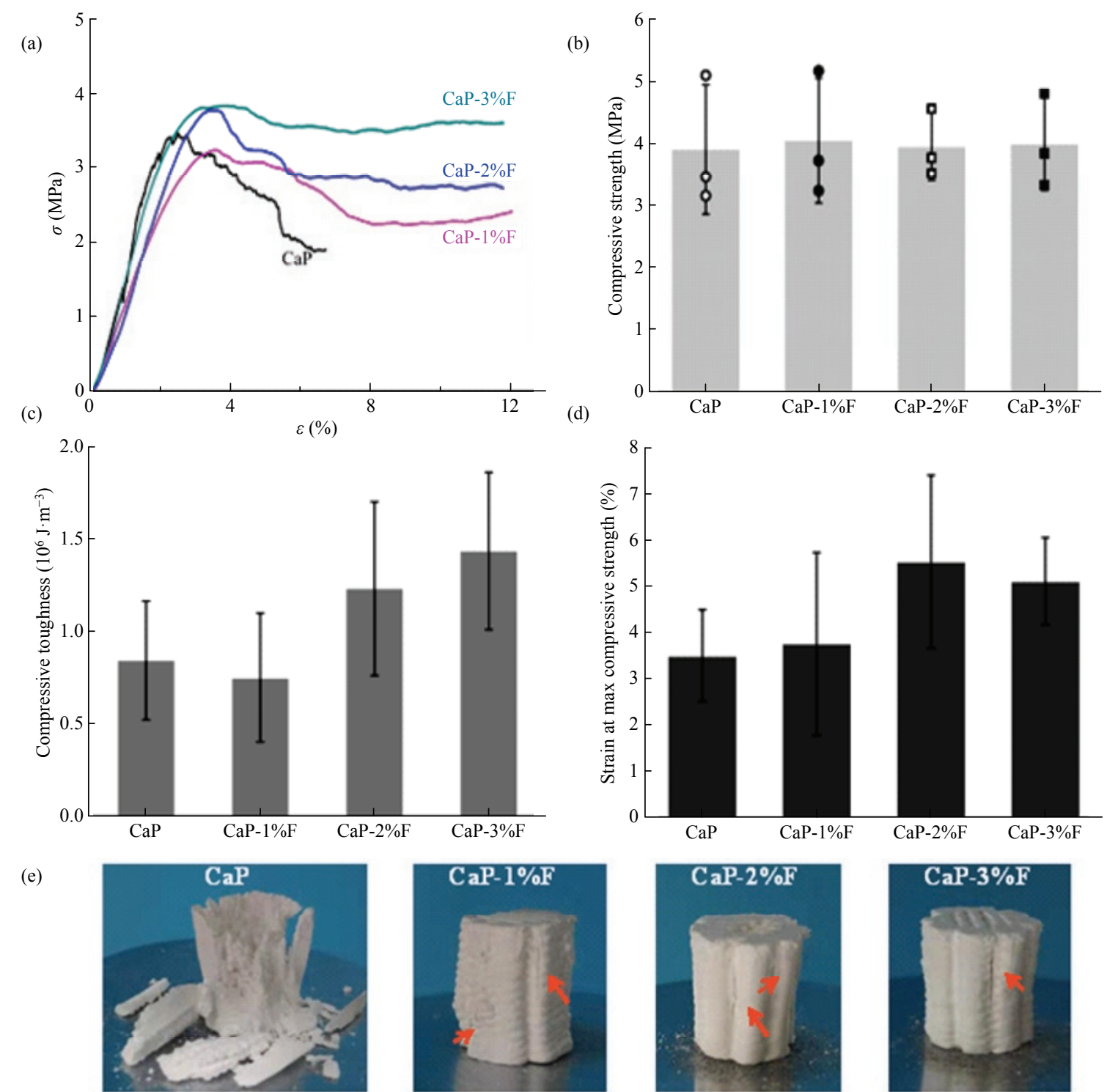

Fig. 8 Mechanical properties of 3D printed CaP scaffolds with different fiber contents. Stress-strain curve (a), compressive strength (b), compressive toughness (c), strain at max compressive strength (d), and photographs of $\mathrm{CaP}-X \% \mathrm{~F}$ scaffold after compressive testing (e). Arrows indicate obvious cracks on the surface of $\mathrm{CaP}-\mathrm{X} \% \mathrm{~F}$ scaffolds.

which could match the compressive strength of cancellous bone ${ }^{[57]}$.

Fig. 9 shows the morphology of cross-sections and surface of $\mathrm{CaP}-\mathrm{X} \% \mathrm{~F}$ scaffolds. The cross-sections of $\mathrm{CaP}-\mathrm{X} \% \mathrm{~F}$ scaffolds appeared as the rougher surface compared to that of CaP scaffold (Figs. $9 a_{2}-9 d_{2}$ ). It indicated the former behavior as ductile fracture but the latter occurred brittle fracture. In the magnified SEM images (Figs. $9 a_{1}-9 a_{4}$ ), the number of PLGA fibers increased obviously with the increasing of PLGA fiber content in cross-section of $\mathrm{CaP}-\mathrm{X} \% \mathrm{~F}$ scaffolds. More- over, PLGA fibers were homogeneously dispersed without agglomeration or intertwining. The high dispersibility of PLGA fibers in CaP scaffolds was mainly attributed to the good surface wettability of non- aggregated PLGA fiber, appropriate content of fibers and the addition mode of fibers into paste compare to previous study ${ }^{[7]}$. Some holes in cross-section were speculated to be left by fiber pull-out in terms of the diameter of PLGA fiber and hole. Thus, PLGA fibers could resist the external force and prevent the propagation of cracks. It was speculated that the toughen mechanism of 

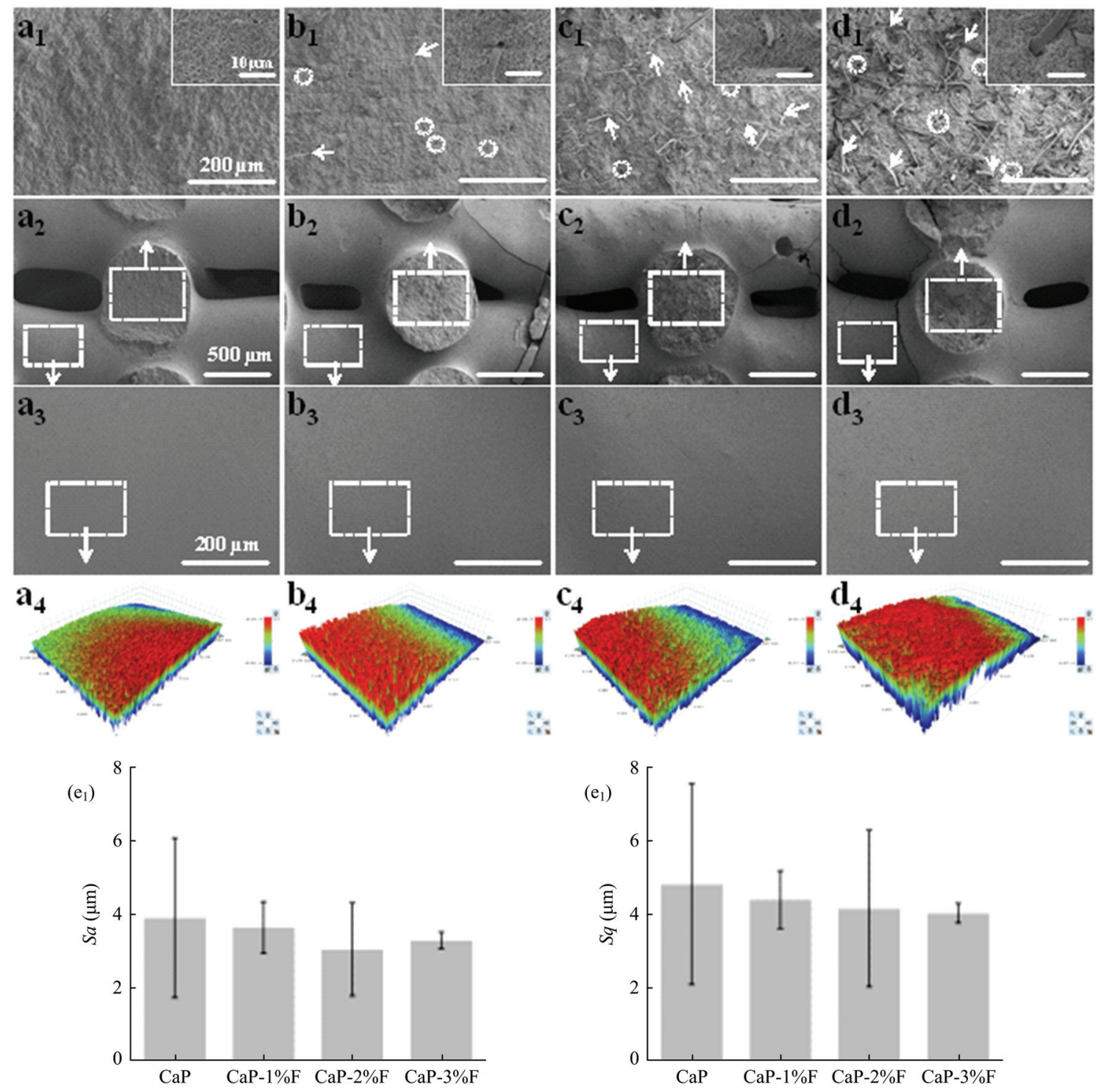

Fig. 9 SEM morphology of cross-sections in CaP- $X \% \mathrm{~F}$ scaffolds after compression testing. $\mathrm{CaP}\left(\mathrm{a}_{1}-\mathrm{a}_{4}\right), \mathrm{CaP}-1 \% \mathrm{~F}\left(\mathrm{~b}_{1}-\mathrm{b}_{4}\right), \mathrm{CaP}-2 \% \mathrm{~F}$ $\left(c_{1}-c_{4}\right)$, and $\mathrm{CaP}-3 \% \mathrm{~F}\left(\mathrm{~d}_{1}-\mathrm{d}_{4}\right)$. Top inset shows the high-magnification morphology of four types of CaP scaffolds. Arrows and circles indicate PLGA fibers and holes produced by pulling out fibers on the cross-section in CaP- $X \% \mathrm{~F}$ scaffolds. $\mathrm{a}_{4}, \mathrm{~b}_{4}, \mathrm{c}_{4}$, and $\mathrm{d}_{4}$ show typical $3 \mathrm{D}$ surface topography of $\mathrm{CaP}, \mathrm{CaP}-1 \% \mathrm{~F}, \mathrm{CaP}-2 \% \mathrm{~F}$ and $\mathrm{CaP}-3 \% \mathrm{~F}$ scaffolds, respectively. The arithmetic mean surface roughness $\left(\mathrm{e}_{1}\right)$ and root mean square surface roughness $\left(\mathrm{e}_{2}\right)$ of the $\mathrm{CaP}-\mathrm{X} \% \mathrm{~F}$ scaffolds were obtained through quantitative calculations.

3D printed $\mathrm{CaP}$ scaffolds was mainly fiber bridging and pull-out effect according to the distribution characteristics and pull-out phenomenon of PLGA fibers in the cross-section as previous report ${ }^{[58]}$.

The surface roughness of $\mathrm{CaP}$ scaffolds plays an important role in the adhesion of cell. Fig. $9 a_{4}-9 d_{4}$ show the 3D surface topographies of $\mathrm{CaP}$ scaffolds by white light interferometer. Figs. $9 \mathrm{e}_{1}$ and $9 \mathrm{e}_{2}$ show the quantitative roughness of CaP scaffolds, $S a$ or $S q$, there was no significantly difference among $\mathrm{CaP}$ scaffolds with dif- ferent fiber contents. No obvious PLGA fibers appeared on the surface of $\mathrm{CaP}$ scaffolds with different fiber contents. Therefore, PLGA fibers did not affect the surface roughness of $\mathrm{CaP}$ scaffolds.

\subsection{Cell proliferation and alkaline phosphatase ac- tivity}

The cell viability of MG-63 is shown in Fig. 10a after co-cultured on $\mathrm{CaP}-\mathrm{X} \% \mathrm{~F}$ scaffolds after $1 \mathrm{~d}, 3 \mathrm{~d}$, $5 \mathrm{~d}$, and $7 \mathrm{~d}$. The reduction rate of alamar-blue 
represented the viability of MG-63 cell ${ }^{[59]}$. The cell viability of $\mathrm{CaP}-X \% \mathrm{~F}$ scaffolds all increased with culture time, which demonstrated the biocompatibility of all four types of CaP scaffolds. Specifically, the incorporation of PLGA fibers did not decrease the activity of MG-63 cells. ALP is a key marker of osteoblasts differentiation at early stage, which is widely used to characterize the osteogenic differentiation potential of biomaterials in many previous studies ${ }^{[4,60,61]}$. The ALP activities of MG-63 cells cultured on the $\mathrm{CaP}-X \% \mathrm{~F}$ scaffolds for $14 \mathrm{~d}$ are shown in Fig. 10b. The ALP ac- tivities of MG-63 cells cultured with CaP- $X \% \mathrm{~F}$ scaffolds were significantly higher than that of control group. It inferred that $\mathrm{CaP}-X \% \mathrm{~F}$ scaffolds had the promoted effect on the osteogenic differentiation of MG-63 cells.

\subsection{Morphology of cell on $\mathrm{CaP}-\mathrm{X} \% \mathrm{~F}$ scaffolds}

The morphology of cell adhesion and spreading on the $\mathrm{CaP}-X \% \mathrm{~F}$ scaffolds is shown in Fig. 11. MG-63 cells were mostly spread on the surface of $\mathrm{CaP}-X \% \mathrm{~F}$ scaffolds as irregular and triangular shape (Figs. 11 $\mathrm{a}_{1}-11 \mathrm{a}_{4}$ ). Fluorescence images of MG-63 cells showed green

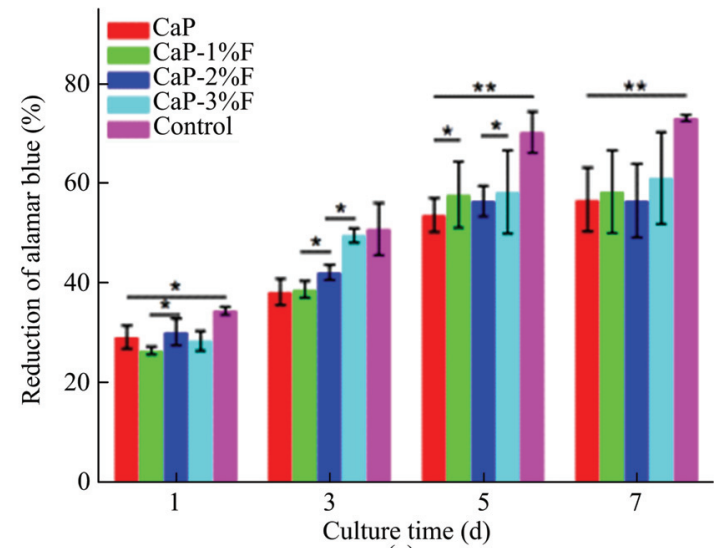

(a)

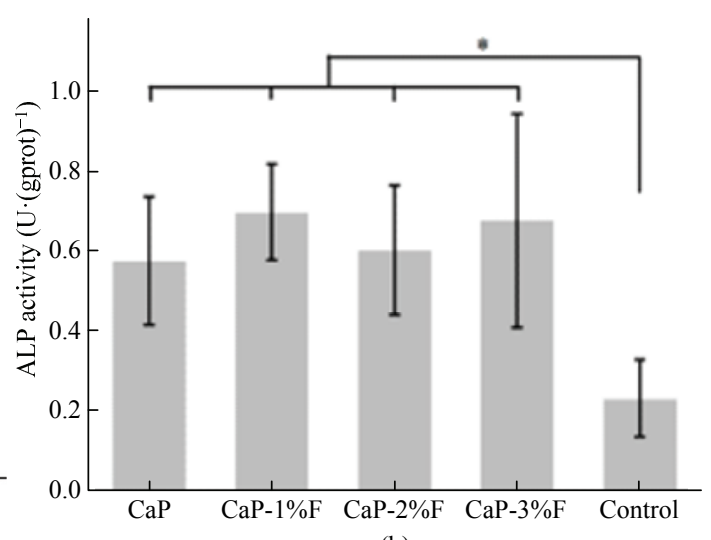

(b)

Fig. 10 The cell viability (a) and ALP activity (b) of MG-63 cell after co-culturing of MG-63 cell and CaP- $X \% \mathrm{~F}$ scaffold for various time points.
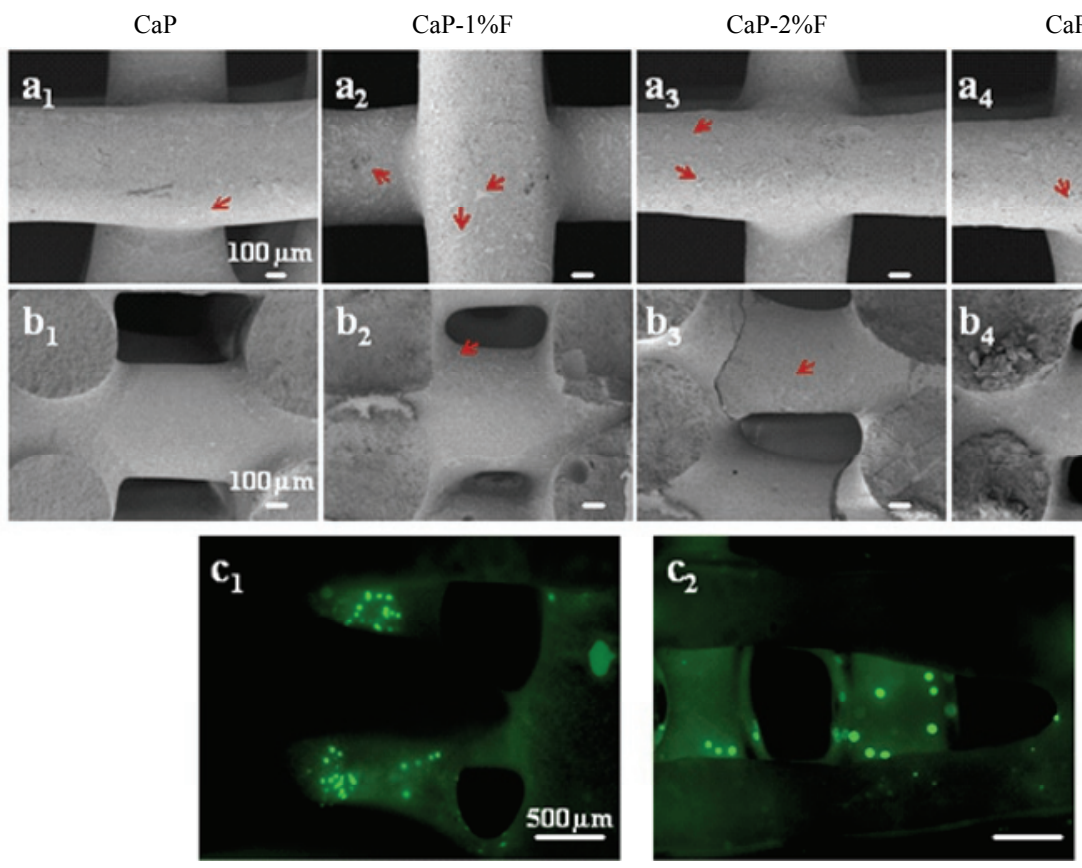

Fig. 11 SEM images of MG-63 cells attachment on the CaP- $X \% \mathrm{~F}$ scaffolds as indicated as the red arrows, (a) Top view, (b) Cross-section view. Images of MG-63 cells stained with calcein-AM after cultured for $3 \mathrm{~d}$ on the CaP scaffold $\left(\mathrm{c}_{1}\right)$ and $\mathrm{CaP}-3 \% \mathrm{~F}$ scaffold $\left(\mathrm{c}_{2}\right)$. 
fluorescence on the surface of 3D printed $\mathrm{CaP}$ scaffold and $\mathrm{CaP}-3 \% \mathrm{~F}$ scaffold (Figs. $11 \mathrm{c}_{1}$ and $11 \mathrm{c}_{2}$ ). Specifically, the MG-63 cells were also observed on the inner surface of $3 \mathrm{D}$ printing porous construct (Figs. $11 b_{1}-11 b_{4}$ ). This result indicated that cell could migrated and grew into the inner pore of $3 \mathrm{D}$ printing scaffolds due to the excellent porous connectivity compared to the traditional uncontrollable porous scaffold, which could be conducive for the delivery of nutrition and metabolic waste.

In the present study, the toughness of 3D printed $\mathrm{CaP}$ scaffolds was effectively improved by the incorporation of fibers. However, mechanical properties of $\mathrm{CaP}$ scaffolds still cannot meet the requirement of load-bearing parts. However, it is not feasible to increase the content of fibers because excessive PLGA fibers will deteriorate the printability of $\mathrm{CaP}$ paste. Furthermore, increasing of the mechanical strength of fiber, improvement of the shear force between fiber and matrix need to be investigated for further improving of mechanical strength of $3 \mathrm{D}$ printing $\mathrm{CaP}$ scaffolds reinforced with fibers.

\section{Conclusion}

In this study, CaP pastes containing well-dispersed PLGA fiber was printed CaP scaffolds by extrusion-based 3D printing, which showed the ductile fracture behavior. The main conclusions were as follows:

(1) It was feasible to prepare the non-aggregated PLGA fibers and the well dispersed PLGA fibers in the liquid phase by combining frozen sections with chemical dispersants.

(2) $\mathrm{CaP}$ pastes with well dispersed PLGA fibers no more than $3 \mathrm{wt} \%$ exhibited the good injectability and formability. Moreover, CaP paste with well dispersed PLGA fibers showed shear thinning behavior. These were conducive to extrusion-based $3 \mathrm{D}$ printing. The addition of PLGA fibers would reduce the setting time of $\mathrm{CaP}$ paste, which would provide the good formability and shape fidelity of the CaP scaffold. This $\mathrm{CaP}$ paste containing PLGA fibers could be printed various complex shape structures by extrusion-based 3D printing.

(3) The well dispersed PLGA fibers significantly increased the toughness of $\mathrm{CaP}$ scaffolds and exhibited the relative superior structural integrity. The main mechanism of PLGA fibers to toughen CaP scaffolds was the fiber pull-out and bridging effect.

(4) The cell proliferation and ALP activity indicated that $3 \mathrm{D}$ printed $\mathrm{CaP}$ scaffold containing PLGA fibers possesses excellent biocompatibility and facilitate osteogenic differentiation ability.

This study provided a new strategy for fiber toughened $\mathrm{CaP}$ scaffold by extrusion-based 3D printing.

\section{Acknowledgment}

This work was supported by the National Natural Science Foundation of China (51372210), Research Fund for the Doctoral Program of Higher Education of China (20130184110023), the Basic Research Foundation Key Project of Sichuan Province (2016JY0011), and the Fundamental Research Funds for the Central Universities (2682020XG04).

We would like to thank Analytical and Testing Center of Southwest Jiaotong University for their assistance with morphology and phase composition analysis.

* All supplementary materials are available at https://doi.org/10.1007/s42235-020-0051-2.

Open Access This article is licensed under a Creative Commons Attribution 4.0 International License, which permits use, sharing, adaptation, distribution and reproduction in any medium or format, as long as you give appropriate credit to the original author(s) and the source, provide a link to the Creative Commons licence, and indicate if changes were made.

The images or other third party material in this article are included in the article's Creative Commons licence, unless indicated otherwise in a credit line to the material. If material is not included in the article's Creative Commons licence and your intended use is not permitted by statutory regulation or exceeds the permitted use, you will need to obtain permission directly from the copyright holder.

To view a copy of this licence, visit http://creativecommons.org/licenses/by/4.0/.

\section{References}

[1] Jeong J, Kim J H, Shim J H, Hwang N S, Heo C Y. Bioactive 
calcium phosphate materials and applications in bone regeneration. Biomaterials Research, 2019, 23, 4.

[2] Anitha A, Joseph J, Menon D, Nair S V, Nair M B. Electrospun yarn reinforced nanoHA composite matrix as a potential bone substitute for enhanced regeneration of segmental defects. Tissue Engineering Part A, 2017, 23, 345-358.

[3] Krueger R, Groll J. Fiber reinforced calcium phosphate cements - On the way to degradable load bearing bone substitutes? Biomaterials, 2012, 33, 5887-5900.

[4] Kunisch E, Gunnella F, Wagner S, Dees F, Maenz S, Bossert J, Jandt K D, Kinne R W. The poly (l-lactid-co-glycolide; PLGA) fiber component of brushite-forming calcium phosphate cement induces the osteogenic differentiation of human adipose tissue-derived stem cells. Biomedical Materials, 2019, 14, 5.

[5] Nair A K, Gautieri A, Chang S W, Buehler M J. Molecular mechanics of mineralized collagen fibrils in bone. Nature Communications, 2013, 4, 1-9.

[6] Yang G, Li X L, He Y, Ma J K, Ni G L, Zhou S B. From nano to micro to macro: Electrospun hierarchically structured polymeric fibers for biomedical applications. Progress in Polymer Science, 2018, 81, 80-113.

[7] Zuo Y, Yang F, Wolke J G C, Li Y B, Jansen J A. Incorporation of biodegradable electrospun fibers into calcium phosphate cement for bone regeneration. Acta Biomaterialia, 2010, 6, 1238-1247.

[8] Manju V, Anitha A, Menon D, Iyer S, Nair S V, Nair M B. Nanofibrous yarn reinforced HA-gelatin composite scaffolds promote bone formation in critical sized alveolar defects in rabbit model. Biomedical Materials, 2018, 13, 065011.

[9] Mulky E, Maniura-Weber K, Frenz M, Fortunato G, Luginbuehl R. Absorbable mineral nanocomposite for biomedical applications: Influence of homogenous fiber dispersity on mechanical properties. Journal of Biomedical Materials Research Part A, 2018, 106, 850-857.

[10] Petre D G, Kucko N W, Abbadessa A, Vermonden T, Polini A, Leeuwenburgh S C G. Surface functionalization of polylactic acid fibers with alendronate groups does not improve the mechanical properties of fiber-reinforced calcium phosphate cements. Journal of the Mechanical Behavior of Biomedical Materials, 2019, 90, 472-483.

[11] Maenz S, Hennig M, Muhlstadt M, Kunisch E, Bungartz M, Brinkmann O, Bossert J, Kinne R W, Jandt K D. Effects of oxygen plasma treatment on interfacial shear strength and post-peak residual strength of a PLGA fiber-reinforced brushite cement. Journal of the Mechanical Behavior of Biomedical Materials, 2016, 57, 347-358.

[12] Maenz S, Kunisch E, Muhlstadt M, Bohm A, Kopsch V, Bossert J, Kinne R W, Jandt K D. Enhanced mechanical properties of a novel, injectable, fiber-reinforced brushite cement. Journal of the Mechanical Behavior of Biomedical Materials, 2014, 39, 328-338.

[13] Zhu Y, Zhang K, Zhao R, Ye X J, Chen X N, Xiao Z W, Yang X, Zhu X D, Zhang K, Fan Y J, Zhang X D. Bone regeneration with micro/nano hybrid-structured biphasic calcium phosphate bioceramics at segmental bone defect and the induced immunoregulation of MSCs. Biomaterials, 2017, 147, 133-144.

[14] Liang L F, Weng J, Feng B, Qu S X. Improving the interconnectivity of chitin-gel-cast porous calcium phosphate ceramics by different acid etching approaches. In: Pricm 5: The Fifth Pacific Rim International Conference on Advanced Materials And Processing, Pts 1-5, Zhong Z Y, Saka H, Kim T H, Holm E A, Han Y F, Xie X S. eds., 2005, 475-479, 2367-2369.

[15] Zhu Y H, Wang Z L, Zhou H L, Li L L, Zhu Q S, Zhang P B. An injectable hydroxyapatite/poly(lactide-co-glycolide) composite reinforced by micro/nano-hybrid poly(glycolide) fibers for bone repair. Materials Science \& Engineering C: Materials for Biological Applications, 2017, 80, 326-334.

[16] Datta P, Vyas V, Dhara S, Chowdhury A R, Barui A. Anisotropy properties of tissues: A basis for fabrication of biomimetic anisotropic scaffolds for tissue engineering. Journal of Bionic Engineering, 2019, 16, 842-868.

[17] Becker S T, Bolte H, Krapf O, Seitz H, Douglas T, Sivananthan S, Wiltfang J, Sherry E, Warnke P H. Endocultivation: 3D printed customized porous scaffolds for heterotopic bone induction. Oral Oncology, 2009, 45, e181-e188.

[18] Zhang L, Yang G J, Johnson B N, Jia X F. Three-dimensional (3D) printed scaffold and material selection for bone repair. Acta Biomaterialia, 2019, 84, 16-33.

[19] Bergmann C J D, Odekerken J C E, Welting T J M, Jungwirth F, Devine D, Boure L, Zeiter S, van Rhijn L W, Telle R, Fischer H, Emans P J. Calcium phosphate based three-dimensional cold plotted bone scaffolds for critical size bone defects. Biomed Research International, 2014, 2014, 852610 .

[20] Zhu H Y, Zhai D, Lin C C, Zhang Y L, Huan Z G, Chang J, Wu C T. 3D plotting of highly uniform $\mathrm{Sr}_{5}\left(\mathrm{PO}_{4}\right)_{2} \mathrm{SiO}_{4}$ bioceramic scaffolds for bone tissue engineering. Journal of Materials Chemistry B, 2016, 4, 6200-6212.

[21] Zhou Z X, Buchanan F, Mitchell C, Dunne N. Printability of 
calcium phosphate: Calcium sulfate powders for the application of tissue engineered bone scaffolds using the 3D printing technique. Materials Science \& Engineering $C$, Materials for Biological Applications, 2014, 38, 1-10.

[22] Kumar A, Mandal S, Barui S, Vasireddi R, Gbureck U, Gelinsky M, Basu B. Low temperature additive manufacturing of three dimensional scaffolds for bone-tissue engineering applications: Processing related challenges and property assessment. Materials Science and Engineering R: Reports, 2016, 103, 1-39.

[23] Fu S Y, Hu H R, Chen J J, Zhu Y F, Zhao S C. Silicone resin derived larnite/C scaffolds via 3D printing for potential tumor therapy and bone regeneration. Chemical Engineering Journal, 2020, 382, 122928.

[24] Shao H F, Ke X R, Liu A, Sun M, He Y, Yang X Y, Fu J Z, Liu Y M, Zhang L, Yang G H, Xu S Z, Gou Z R. Bone regeneration in $3 \mathrm{D}$ printing bioactive ceramic scaffolds with improved tissue/material interface pore architecture in thin-wall bone defect. Biofabrication, 2017, 9, 025003.

[25] Kang Z R, Yu B, Fu S Y, Li D J, Zhang X, Qian Z, Zhong Z Y, Yu B Q, Ding H F, Zhu Y F, Huang J M. Three-dimensional printing of $\mathrm{CaTiO}_{3}$ incorporated porous beta- $\mathrm{Ca}_{2} \mathrm{SO}_{4}$ composite scaffolds for bone regeneration. Applied Materials Today, 2019, 16, 132-140.

[26] Kang N U, Hong M W, Kim Y Y, Cho Y S, Lee S J. Development of a powder extruder system for dual-pore tissue-engineering scaffold fabrication. Journal of Bionic Engineering, 2019, 16, 686-695.

[27] Wang H N, Bongio M, Farbod K, Nijhuis A W G, van den Beucken J, Boerman O C, van Hest J C M, Li Y B, Jansen J A, Leeuwenburgh S C G. Development of injectable organic/inorganic colloidal composite gels made of self- assembling gelatin nanospheres and calcium phosphate nanocrystals. Acta Biomaterialia, 2014, 10, 508-519.

[28] Wei J J, Luo X M, Chen M H, Lu J F, Li X H. Spatial distribution and antitumor activities after intratumoral injection of fragmented fibers with loaded hydroxycamptothecin. Acta Biomaterialia, 2015, 23, 189-200.

[29] Bohner M. Calcium orthophosphates in medicine from ceramics to calcium phosphate cements. Injured, 2000, 31, D37-D47.

[30] Ginebra M P, Rilliard A, Fernandez E, Elvira C, San Roman J, Planell J A. Mechanical and rheological improvement of a calcium phosphate cement by the addition of a polymeric drug. Journal of Biomedical Materials Research, 2001, 57, 113-118.

[31] Montufar E B, Maazouz Y, Ginebra M P. Relevance of the setting reaction to the injectability of tricalcium phosphate pastes. Acta Biomaterialia, 2013, 9, 6188-6198.

[32] Driessens F C M, Boltong M G, Bermudez O, Planell J A. Formulation and setting times of some calcium orthophosphate cements: A pilot study. Journal of Materials Science, Materials in Medicine, 1993, 4, 503-508.

[33] Chen Y, Wang Y H, Yang Q, Liao Y X, Zhu B, Zhao G R, Shen R, Lu X B, Qu S X. A novel thixotropic magnesium phosphate-based bioink with excellent printability for application in 3D printing. Journal of Materials Chemistry B, $2018,6,4502-4513$.

[34] Liu Z G, Qu S X, Zheng X T, Xiong X, Fu R, Tang K Y, Zhong $\mathrm{Z}$ D, Weng J. Effect of polydopamine on the biomimetic mineralization of mussel-inspired calcium phosphate cement in vitro. Materials Science and Engineering C, Materials for Biological Applications, 2014, 44, 44-51.

[35] Zhou Z, Cunningham E, Lennon A, McCarthy H O, Buchanan F, Dunne N. Development of three-dimensional printing polymer-ceramic scaffolds with enhanced compressive properties and tuneable resorption. Materials Science \& Engineering C, Materials for Biological Applications, 2018, 93, 975-986.

[36] Muller M, Becher J, Schnabelrauch M, Zenobi-Wong M. Nanostructured Pluronic hydrogels as bioinks for 3D bioprinting. Biofabrication, 2015, 7, 035006.

[37] Lee J, Kim G. Three-dimensional hierarchical nanofibrous collagen scaffold fabricated using fibrillated collagen and pluronic F-127 for regenerating bone tissue. ACS Applied Materials and Interfaces, 2018, 10, 35801-35811.

[38] Kurusu R S, Demarquette N R. Wetting of hydrophilic electrospun mats produced by blending SEBS with PEO-PPO-PEO copolymers of different molecular weight. Langmuir, 2016, 32, 1846-1853.

[39] Jeon S W, Kang S H, Choi J C, Kim T H. Dispersion of boron nitride nanotubes by pluronic triblock copolymer in aqueous solution. Polymers, 2019, 11, 582.

[40] Arutyunyan N R, Baklashev D V, Obraztsova E D. Suspensions of single-wall carbon nanotubes stabilized by pluronic for biomedical applications. European Physical Journal B, 2010, 75, 163-166.

[41] Huang P, Li P, Zhao J S, Qu S X, Feng B, Weng J. Mechanical activation reinforced porous calcium phosphate cement. Journal of Inorganic Materials, 2015, 30, 432-438.(in Chinese)

[42] Combes C, Tadier S, Galliard H, Girod-Fullana S, Charvillat C, Rey C, Auzely-Velty R, El Kissi N. Rheological properties of calcium carbonate self-setting injectable paste. Acta 
Biomaterialia, 2010, 6, 920-927.

[43] Zhou X, Li Z. Characterization of rheology of fresh fiber reinforced cementitious composites through ram extrusion. Materials and Structures, 2005, 38, 17-24.

[44] Parveen S, Rana S, Fangueiro R, Paiva M C. Microstructure and mechanical properties of carbon nanotube reinforced cementitious composites developed using a novel dispersion technique. Cement and Concrete Research, 2015, 73, 215-227.

[45] Castro A G B, Polini A, Azami Z, Leeuwenburgh S C G, Jansen J A, Yang F, van den Beucken J. Incorporation of PLLA micro-fillers for mechanical reinforcement of calcium-phosphate cement. Journal of the Mechanical Behavior of Biomedical Materials, 2017, 71, 286-294.

[46] Sahin E, Kalyon D M. The rheological behavior of a fast-setting calcium phosphate bone cement and its dependence on deformation conditions. Journal of the Mechanical Behavior of Biomedical Materials, 2017, 72, 252-260.

[47] Akkineni A R, Luo Y X, Schumacher M, Nies B, Lode A, Gelinsky M. 3D plotting of growth factor loaded calcium phosphate cement scaffolds. Acta Biomaterialia, 2015, 27, 264-274.

[48] Lode A, Meissner K, Luo Y X, Sonntag F, Glorius S, Nies B, Vater C, Despang F, Hanke T, Gelinsky M. Fabrication of porous scaffolds by three-dimensional plotting of a pasty calcium phosphate bone cement under mild conditions. Journal of Tissue Engineering and Regenerative Medicine, 2014, 8, 682-693.

[49] Maazouz Y, Montufar E B, Guillem-Marti J, Fleps I, Ohman C, Persson C, Ginebr M P. Robocasting of biomimetic hydroxyapatite scaffolds using self-setting inks. Journal of Materials Chemistry B, 2014, 2, 5378-5386.

[50] Brunner T J, Grass R N, Bohner M, Stark W J. Effect of particle size, crystal phase and crystallinity on the reactivity of tricalcium phosphate cements for bone reconstruction. Journal of Materials Chemistry, 2007, 17, 4072-4078.

[51] Qi X, Pei P, Zhu M, Du X Y, Xin C, Zhao S C, Li X L, Zhu Y F. Three dimensional printing of calcium sulfate and mesoporous bioactive glass scaffolds for improving bone regeneration in vitro and in vivo. Scientific Reports, 2017, 7,
42556.

[52] Guo X H, Gao H C, Liu X, Diao J J, Shi X T, Zhao N R, Wang Y J. Porous Li-containing biphasic calcium phosphate scaffolds fabricated by three-dimensional plotting for bone repair. RSC Advances, 2017, 7, 34508-34516.

[53] Vasconcellos L A, dos Santos L A. Calcium phosphate cement scaffolds with PLGA fibers. Materials Science and Engineering C, 2013, 33, 1032-1040.

[54] Buchanan F, Gallagher L, Jack V, Dunne N. Short-fibre reinforcement of calcium phosphate bone cement. Proceedings of the Institution of Mechanical Engineers Part H, 2007, 221, 203-211.

[55] Ogasawara T, Sawamura T, Maeda H, Obata A, Hirata H, Kasuga T. Enhancing the mechanical properties of calcium phosphate cements using short-length polyhydroxyalkanoate fibers. Journal of the Ceramic Society of Japan, 2016, 124, 180-183.

[56] Williams J M, Adewunmi A, Schek R M, Flanagan C L, Krebsbach P H, Feinberg S E, Hollister S J, Das S. Bone tissue engineering using polycaprolactone scaffolds fabricated via selective laser sintering. Biomaterials, 2005, 26, 4817-4827.

[57] Fu Q, Saiz E, Rahaman M N, Tomsia A P. Toward strong and tough glass and ceramic scaffolds for bone repair. Advanced Functional Materials, 2013, 23, 5461-5476.

[58] Zhang J T, Liu W, Schnitzler V, Tancret F, Bouler J M. Calcium phosphate cements for bone substitution: Chemistry, handling and mechanical properties. Acta Biomaterialia, 2014, 10, 1035-1049.

[59] Rampersad S N. Multiple applications of alamar blue as an indicator of metabolic function and cellular health in cell viability bioassays. Sensors, 2012, 12, 12347-12360.

[60] Yang C, Wang X Y, Ma B, Zhu H B, Huan Z G, Ma N, Wu C T, Chang J. 3D-printed bioactive $\mathrm{Ca}_{3} \mathrm{SiO}_{5}$ bone cement scaffolds with nano surface structure for bone regeneration. ACS Applied Materials \& Interfaces, 2017, 9, 5757-5767.

[61] Du X Y, Yu B, Pei P, Ding H F, Yu B Q, Zhu Y F. 3D printing of pearl/ $/ \mathrm{CaSO}_{4}$ composite scaffolds for bone regeneration. Journal of Materials Chemistry B, 2018, 6, 499-509. 